\title{
The Influence of Grain Structure on Intermetallic Compound Layer Growth Rates in Fe-Al Dissimilar Welds
}

\author{
LEI XU, JOSEPH D. ROBSON, LI WANG, and PHILIP B. PRANGNELL
}

The thickness of the intermetallic compound (IMC) layer that forms when aluminum is welded to steel is critical in determining the properties of the dissimilar joints. The IMC reaction layer typically consists of two phases ( $\eta$ and $\theta$ ) and many attempts have been made to determine the apparent activation energy for its growth, an essential parameter in developing any predictive model for layer thickness. However, even with alloys of similar composition, there is no agreement of the correct value of this activation energy. In the present work, the IMC layer growth has been characterized in detail for AA6111 aluminum to DC04 steel couples under isothermal annealing conditions. The samples were initially lightly ultrasonically welded to produce a metallic bond, and the structure and thickness of the layer were then characterized in detail, including tracking the evolution of composition and grain size in the IMC phases. A model developed previously for Al-Mg dissimilar welds was adapted to predict the coupled growth of the two phases in the layer, whilst accounting explicitly for grain boundary and lattice diffusion, and considering the influence of grain growth. It has been shown that the intermetallic layer has a submicron grain size, and grain boundary diffusion as well as grain growth plays a critical role in determining the thickening rate for both phases. The model was used to demonstrate how this explains the wide scatter in the apparent activation energies previously reported. From this, process maps were developed that show the relative importance of each diffusion path to layer growth as a function of temperature and time.

DOI: $10.1007 / \mathrm{s} 11661-017-4352-\mathrm{y}$

(C) The Author(s) 2017. This article is an open access publication

\section{INTRODUCTION}

JOINING aluminum to steel is an essential technology for lightweight, cost-effective automotive body structures (e.g., Reference 1). Whilst mechanical fastening is a proven method, dissimilar welding has a number of advantages, with solid-state ultrasonic and friction stir methods having the most promise. ${ }^{[2]}$ However, it has been shown that control of the thermodynamically unavoidable interfacial reaction between aluminum and iron is one of the most critical issues in determining the performance of dissimilar Al-steel joints. ${ }^{[1,3,4]}$ The principle reason for poor joint performance is the growth of a brittle intermetallic compound (IMC) reaction layer

LEI XU, JOSEPH D. ROBSON, and PHILIP B. PRANGNELL are with the School of Materials, University of Manchester, Manchester, M13 9PL, UK. Contact e-mail: joseph.d.robson@ manchester.ac.uk LI WANG is with Advanced Manufacturing Engineering, Jaguar Land Rover Limited, Abbey Rd, Coventry, CV3 4LF, UK.

The original version of this article was revised due to a retrospective Open Access order.

Manuscript submitted April 4, 2017.

Article published online October 10, 2017 between the two metals at the joint interface, which reduces their maximum strength but, more importantly, leads to low energy absorption during failure. ${ }^{[4,5]}$

In order to investigate the growth behavior of the IMC layers and quantify the reaction kinetics, there have been several studies of Al-steel diffusion couples during either welding or isothermal heat treatment (e.g., References 1, 3, $4,6)$. In most cases, a two-phase reaction layer consisting of $\eta\left(\mathrm{Fe}_{2} \mathrm{Al}_{5}\right)$ and $\theta\left(\mathrm{FeAl}_{3}\right)$ is reported to form at the interface in dissimilar A - steel combinations. The $\eta$ phase generally dominates the IMC layer thickness. ${ }^{[6]}$ Therefore, most previous studies have mainly focused on the growth behavior of the $\eta$ phase and have paid less attention to the contribution of the $\theta\left(\mathrm{FeAl}_{3}\right)$ layer. The usual way to interpret IMC layer growth kinetics is to fit the thickness as a function of time to a parabolic law, which is expected for the case of lattice diffusion-controlled growth:

$$
x^{2}=k t,
$$

where $x$ is the thickness of IMC layer (m) after reaction time $t(\mathrm{~s})$, while $k$ is the rate constant, with dimensions of $\mathrm{m}^{2} \mathrm{~s}^{-1}$. The rate constant is temperature dependent and expected to follow an Arrhenius relationship ${ }^{[6]}$ : 


$$
k=k_{0} \exp \left(\frac{-Q}{R T}\right)
$$

$k_{0}$ is the pre-exponential factor; $Q$ is an effective activation energy $\left(\mathrm{J} \mathrm{mol}^{-1}\right) ; R$ is the gas constant $\left(\mathrm{J} \mathrm{K}^{-1} \mathrm{~mol}^{-1}\right.$ ); and $T$ is the reaction temperature $(\mathrm{K})$.

It is common practice to fit experimental data at different temperatures to derive values for $k_{0}$ and $Q$. Examples of effective activation energies for $\eta$ phase growth determined in this way are shown in Table I. It is clear that there is no agreement on a single value for the activation energy, with factor 4 differences between the smallest and largest reported values. This means that the simple parabolic law cannot be used in a predictive capacity, since the calculated layer thickness is very dependent on the value for activation energy chosen. Whilst some difference in this parameter may be attributed to the data obtained for different alloy compositions, this is not the most important factor in explaining the range of values reported. Similarly, whilst some of the studies were performed with aluminum in the liquid state, this also does not explain the differences, since the same diffusion path through the (solid) IMC will control growth rate. It is also clear from the data that there is no systematic variation in activation energy that can be explained by either the state of the aluminum or details of the alloy composition. Indeed, the lowest $\left(74 \mathrm{~kJ} \mathrm{~mol}^{-1}\right)$ and highest $\left(281 \mathrm{~kJ} \mathrm{~mol}^{-1}\right) Q$ values were both determined using pure $\mathrm{Al}$ to pure Fe couples.

The problem with this approach is that it is too simplistic, and the effective activation energy has little physical significance. This is because the rate constant $(k)$ is dependent on many factors, which include the solubility range in the IMC layer, the interdiffusion coefficient of the diffusing species, and the diffusion pathway. ${ }^{[7]}$ Inferring any mechanism (e.g., identifying a rate controlling species) from fitted activation energy values is therefore erroneous. Instead, a more detailed understanding of the layer growth kinetics is needed, which can then be captured in a model that better considers the essential physics of the process.

A more physically realistic model for intermetallic layer growth in a reactive couple has been previously developed by Wang et al. ${ }^{[8]}$ and applied to the case of $\mathrm{Al}$ to $\mathrm{Mg}$ dissimilar joints, with good agreement to experimental results from annealing experiments. The Al-Mg couple also leads to the formation of a two-phase intermetallic layer structure, similar to the Al-Fe case. The model is based on extending a reactive interdiffusion model developed by Kajihara ${ }^{[7,9]}$ for one-phase layers to the two-phase problem. The model properly accounts for the effect of the interfacial compositions on the layer growth, and the boundary conditions that are enforced at the interface between the phases involved. ${ }^{[8]}$ Both grain boundary and lattice diffusion are also accounted for. This was shown to be essential in correctly capturing the growth kinetics in the Al-Mg system, since for the grain sizes typically encountered in the IMC layer, grain boundary diffusion generally makes a significant contribution to the overall solute flux.

In the present study, this dual-phase diffusion model was used to attempt to predict the growth behavior of the IMC layer in $\mathrm{Fe}-\mathrm{Al}$ dissimilar couples during isothermal heat treatment. By explicitly considering grain boundary and lattice diffusion pathways, it is possible to determine the significance of both mechanisms and how this is influenced by growth conditions (e.g., temperature). As part of this exercise, detailed analysis was performed by electron microscopy of the growth rate and microstructure of the IMC phases that formed, including measurements of the grain size evolution within each IMC layer as it grows and the composition gradients within each phase.

\section{EXPERIMENTAL PROCEDURES}

Two sets of samples were used in this investigation, both produced by welding together a DC04 low (0.08 wt pct) carbon formable automotive steel to an AA6111 Al-Mg-Si alloy. Both materials were in the form of flat sheets of dimensions $100 \times 25 \times 1 \mathrm{~mm}$, and were lightly ground prior to welding. To produce diffusion couple samples for isothermal heat treatments, these materials were first lightly pre-welded by Ultrasonic Metal Welding (UMW) using a Sonobond MH2016 dual-head machine with a nominal power of $2.5 \mathrm{~kW}$, pressure of 29 $\mathrm{MPa}$, and a welding time of 1.5 seconds. An overlap region of $25 \times 25 \mathrm{~mm}$ was used and the vibration direction was parallel to the long dimension of the weld coupons. The pre-welding procedure was used to break up the surface oxide and enable metal-metal bonding to take place. This led to only a thin $\sim 1 \mu \mathrm{m}$ continuous IMC layer formed at the interface. These lightly pre-welded samples were then isothermally annealed in the temperature range $673 \mathrm{~K}$ to $843 \mathrm{~K}\left(400{ }^{\circ} \mathrm{C}\right.$ to 570 ${ }^{\circ} \mathrm{C}$ ) for times increasing up to 8 hours.

Metallographic cross sections were prepared from the welded and heat-treated samples by grinding and polishing, using standard techniques, before observation

Table I. Activation Energies Reported for $\eta$ Phase from Previously Reported Heat-Treatment Studies Between Aluminum and Iron (* = Aluminum in Liquid Phase)

\begin{tabular}{|c|c|c|c|}
\hline Researchers & Activation Energy $\left(\mathrm{kJ} \mathrm{mol}^{-1}\right)$ & Temperature $\left[\mathrm{K}\left({ }^{\circ} \mathrm{C}\right)\right]$ & Materials \\
\hline Bouayad et al..$^{[13]}$ & 74.1 & $1073(800)$ & pure $\mathrm{Al}{ }^{*}$-pure $\mathrm{Fe}$ \\
\hline Denner and Jones ${ }^{[14]}$ & $170-195$ & $1044(771)$ & pure $\mathrm{Al}^{*}$-Mild steel \\
\hline Eggeler et al. ${ }^{[15]}$ & $34-155$ & $1059(786)$ & pure $\mathrm{Al}$ *-Low carbon steel \\
\hline Naoi et al. ${ }^{[6]}$ & 281 & $873-923(600-650)$ & pure Al-pure Fe \\
\hline Springer et al. ${ }^{[3]}$ & 190 & $873(600)$ & pure aluminum-low-carbon steel \\
\hline Tang et al. ${ }^{[16]}$ & 123 & $953-1043(680-770)$ & pure $\mathrm{Al} *$-pure $\mathrm{Fe}$ \\
\hline
\end{tabular}


by scanning electron microscopy (SEM) using a high-resolution FEI Magellan field emission gun (FEG) microscope. The average layer thickness was determined from the net area of the IMC layer divided by the interface length. This method enabled a reliable thickness to be determined even when the layer had large local fluctuations.

Electron back scatter diffraction (EBSD) was used to identify the phases within the IMC layer and determine their grain structure. Samples were also prepared from selected positions for transmission electron microscopy (TEM) using a Novalab 660 Focussed Ion Beam (FIB) with a $\mathrm{Ga}^{+}$ion accelerating voltage of $30 \mathrm{kV}$ to produce foils using the lift-out technique. The TEM samples were analyzed in an FEI Tecnai TF30 microscope operating at $300 \mathrm{kV}$.

\section{MODELING}

\section{A. The Dual-IMC Phase Diffusion Model}

The model used here has been previously applied to predict IMC formation in $\mathrm{Al}$ to $\mathrm{Mg}$ joints ${ }^{[8]}$ where an IMC bi-layer consisting of two phases with different thickening constants also forms. In this work, an identical approach was used, but the model parameters were recalibrated for the $\eta$ and $\theta$ phases that form in the present system, rather than the $\mathrm{Al}_{3} \mathrm{Mg}_{2}$ and $\mathrm{Mg}_{17} \mathrm{Al}_{12}$ phases in the Al-Mg couple. A flow chart showing the operation of the model is given in Figure 1(a). The boundary conditions and schematic concentration profile are shown in Figure 1(b).

Grain boundary diffusion and the dynamic effect of grain growth in the IMC layer during thickening are included in the model. Grain boundary diffusion makes a contribution to the overall solute flux that depends on the grain size and effective grain boundary width. The effective diffusivity (combining lattice and grain boundary effects) can be written as ${ }^{[\mathrm{P} 0]}$

$$
D_{\text {eff }}=g D_{\mathrm{gb}}+(1-g) D_{l},
$$

where $D_{\mathrm{l}}$ and $D_{\mathrm{gb}}$ are the interdiffusion coefficients for lattice diffusion and grain boundary diffusion, respectively, expressed by an Arrhenius law similar to Eq. [2], and $g$ is the relative grain boundary area fraction, described by

$$
g=\frac{q \delta}{L},
$$

where $q$ is a numerical factor relating to the grain shape; $\delta$ is grain boundary width; and $L$ is the grain size. $\delta$ is usually assumed to be $\sim 3$ times the atomic diameter. ${ }^{[10]}$ For columnar IMC grain structures commonly found in the Al-Fe system, ${ }^{[1,3,4,6]} q$ can be taken as one, and $L$ is the average grain width.

In a system with an IMC bi-layer, there are three interface positions to be tracked, as shown in Figure 1(b). Once these positions are known, the layer thickness and thus effective parabolic thickening constant can be calculated for each phase. Once the temperature dependency of the effective parabolic thickening constant is known, the effective activation energy for the thickening process of each individual IMC layer can be deduced.

As discussed in Reference 8, the model describes the relationship between the composition profiles and the interdiffusion coefficients of the chosen species in the matrix and IMC phases requiring 4 parameters for an IMC bi-layer. Knowing the interdiffusion coefficients, the concentration profiles can be calculated or knowing

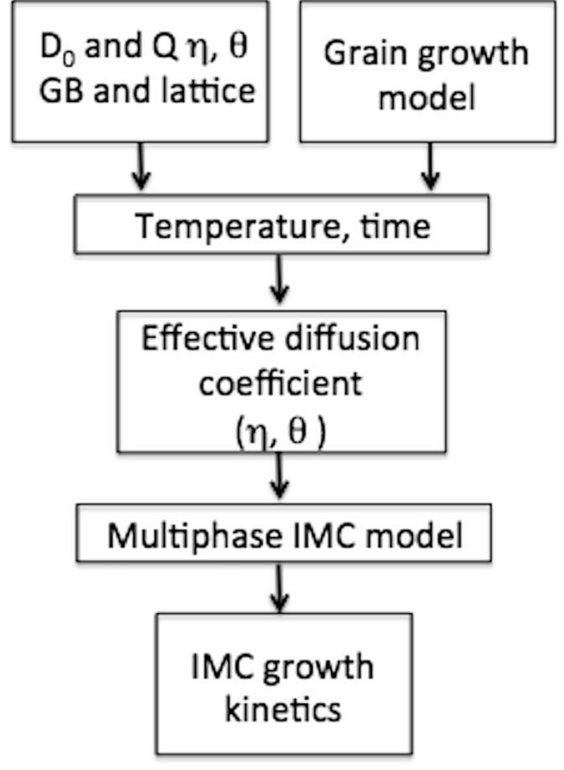

(a)

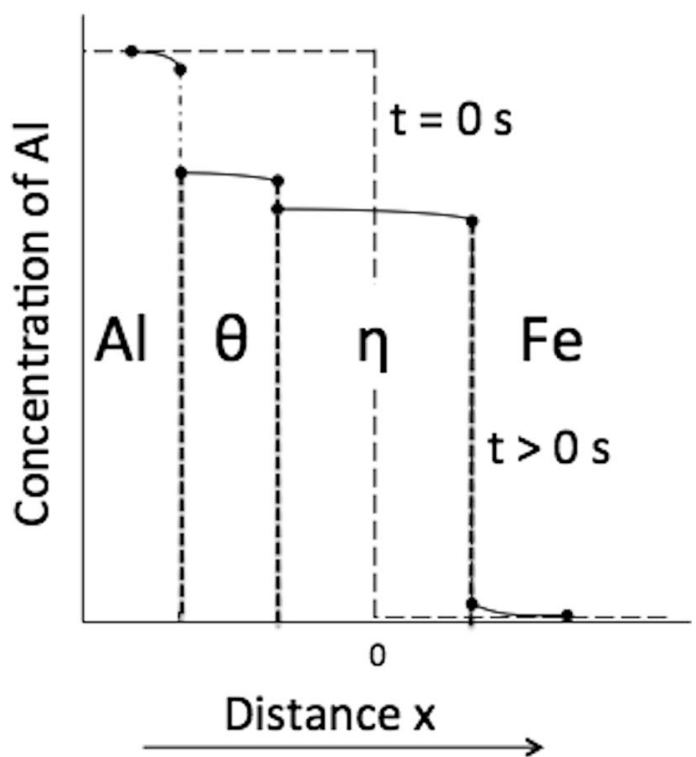

(b)

Fig. 1-Illustration of the principles of the dual-layer 1-D IMC reaction model developed by Wang et al. that includes grain boundary diffusion and grain growth ${ }^{[8]}$; (a) flow diagram, (b) schematic interfacial diffusion profile. 
the composition profiles, the interdiffusion coefficients can be calculated. In the present work, the solute composition profiles were measured and used to determine effective interdiffusion coefficients. The effective interdiffusion coefficient for each phase is made up of a contribution from both lattice and grain boundary diffusion, as shown in Eq. [3]. By measuring the grain size in the layer at the same time as determining the solute composition profile, Eq. [3] can be used to determine separately the lattice and grain boundary contributions to the interdiffusion coefficient. Once this is known, the model can then be applied in the forward direction to predict the layer thickness for different grain sizes.

\section{B. Grain Growth}

As demonstrated later, it is often found that as an IMC layer grows, it simultaneously undergoes grain growth. IMC reaction layers also often have extremely find grain sizes when they first form. ${ }^{[3]}$ Grain growth will change the grain size and hence can potentially greatly influence the contributions of lattice and grain boundary diffusion. To account for this, a simple grain growth law was incorporated into the model, as described in Reference 8 . This states that the grain size varies with time as ${ }^{[11]}$

$$
L_{2}^{n}-L_{1}^{n}=K\left(t_{2}-t_{1}\right)
$$

where $L_{1}$ is the average grain size at the time $t_{1} ; L_{2}$ is the average grain size at the time $t_{2} ; n$ is the exponent factor; and $K$ is a temperature-dependent constant which can be expressed as an Arrhenius relationship with an activation energy and pre-factor (in an identical way to Eq. [2]).

Measured values of the exponent $(n)$ range from 2 to 4 for different metals. ${ }^{[1]}$ This classic grain growth model is valid for equiaxed grains. For columnar grains, which are often observed in the IMC layer formed in a diffusion couple, if only the widening of grains is considered, Eq. [5] can also be applied, but the grain size is instead taken as the average width of the columnar grains measured from 2-D section.

Since the activation energy, pre-factor, and exponent in the grain growth law are difficult to predict, these are found by calibrating Eq. [5] to fit experimental grain growth kinetics. Once the model has been fitted, it may be used to predict grain growth at other temperatures.

\section{RESULTS AND DISCUSSION}

\section{A. IMC Reaction Layer Microstructure Development}

In the UMW joints, a nearly continuous IMC layer had already formed in the pre-welding stage, which had an average thickness of $0.8 \mu \mathrm{m}$ (Figure 2(a)). In the as-welded condition, the $\eta$ and $\theta$ phases were identified
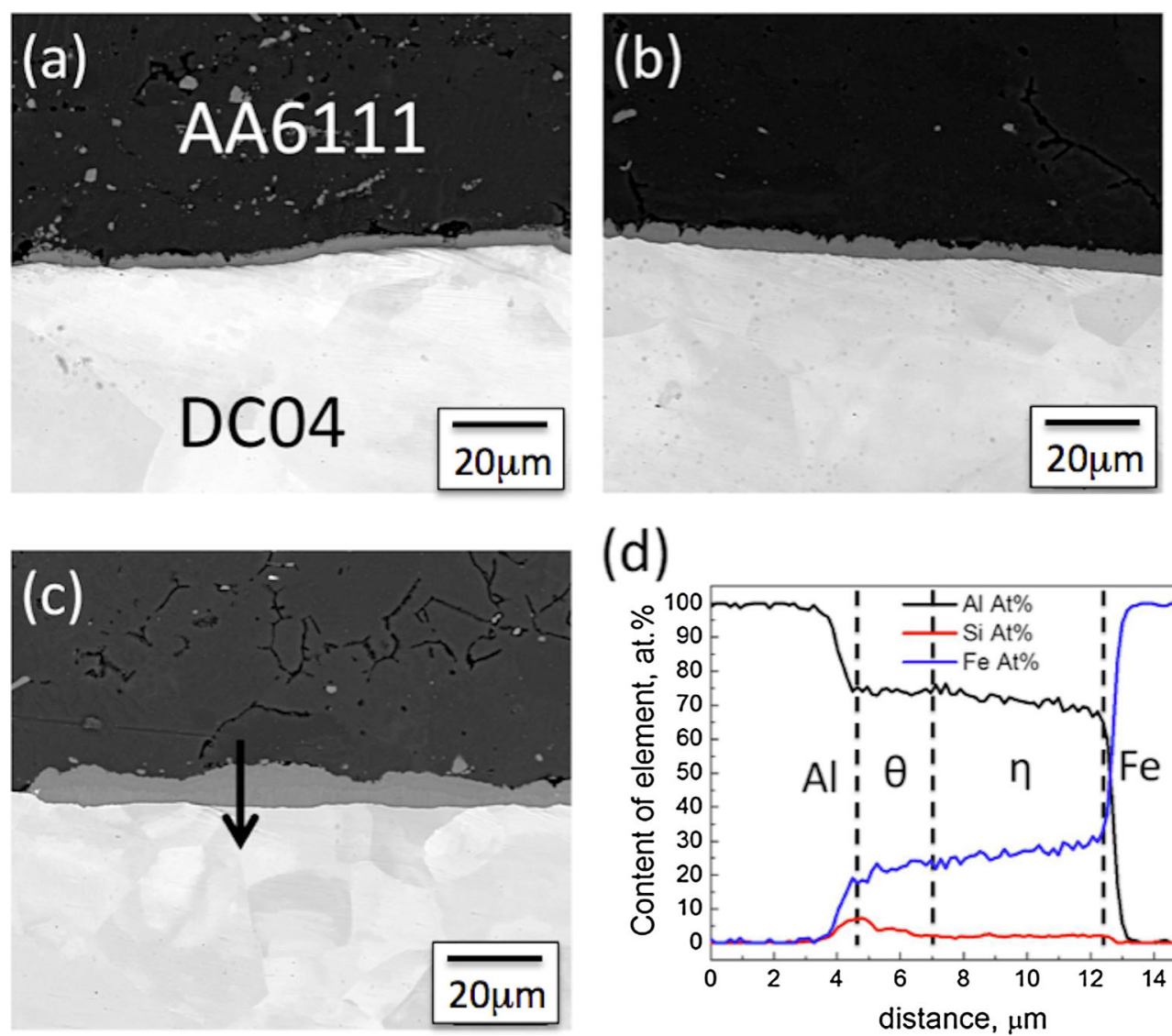

(d)

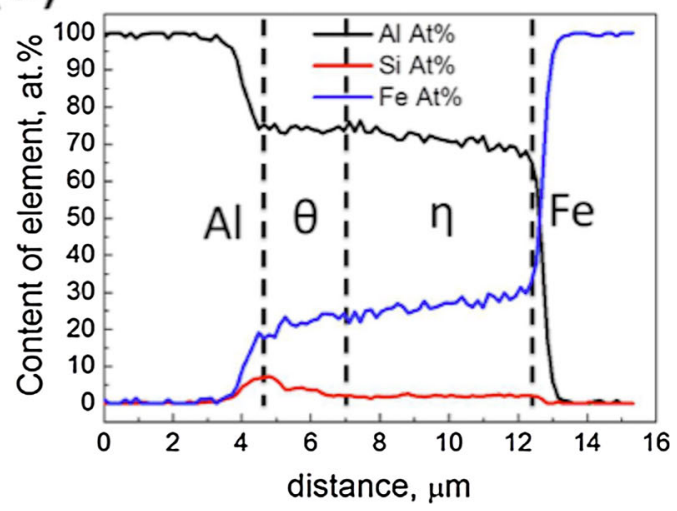

Fig. 2-Microstructure development during annealing of the IMC layers in the UMW joints after heat treatment at $773 \mathrm{~K}\left(500{ }^{\circ} \mathrm{C}\right)$ for $(a) 0$, $(b)$ 10, and (c) 30 min. (d) EDX line scan results along the arrow in (c) after 30 min. 
using micro-diffraction (Figure 3) in the TEM to be already present as dual sublayers, with the $\eta$ phase on the steel side and the $\theta$ phase on the aluminum side of the joint. The IMC layer became thicker during annealing, but was still not fully uniform even after annealing for 30 minutes at $773 \mathrm{~K}\left(500{ }^{\circ} \mathrm{C}\right)$ (Figure 2(c)); such an uneven IMC layer has been commonly observed in the Al-Fe system in several previous studies. This has been attributed to the mechanism by which the IMC forms, nucleating first as isolated islands, which then grow and merge. Thicker regions therefore correspond to regions where the islands first nucleated. ${ }^{[1,3,4,6]}$ The fluctuations in the total thickness of the layer are on the order of $1 \mu \mathrm{m}$, and the amplitude of this fluctuation is preserved as the layer thickens.
When viewed at high magnification (Figure 3(c,d)), it was apparent that both phases had a very fine columnar grain structure and prior to heat treatment the total layer thickness was about $0.8 \mu \mathrm{m}$ (Figure 3(a)). With static heat treatments, both the $\eta$ and $\theta$ sublayers grew thicker, but the $\eta$ phase grew faster than $\theta$ and eventually became much thicker than the $\theta$ phase, while grain growth occurred simultaneously in both phases, which can also be seen in the TEM images in Figure 3 (note the different scales). For longer reaction times, it became possible to employ EBSD phase mapping and, in the example shown in Figure 4 after 2 hours exposure at $773 \mathrm{~K}\left(500{ }^{\circ} \mathrm{C}\right)$, it can be seen that the $\eta$ phase comprised about 80 pct of the layer thickness. In such samples with thick reaction layers, cracks formed very

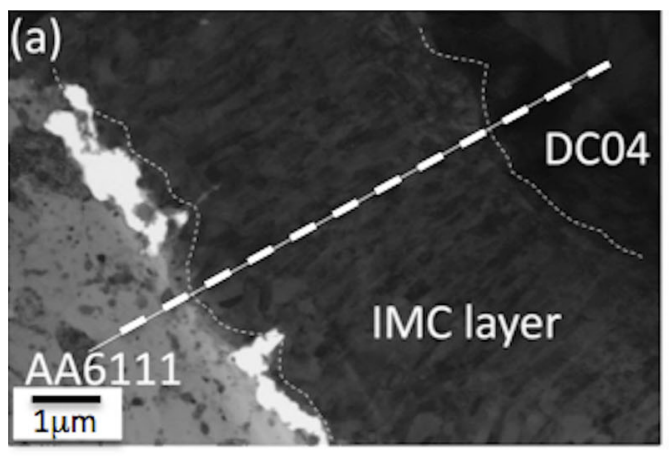

(b)
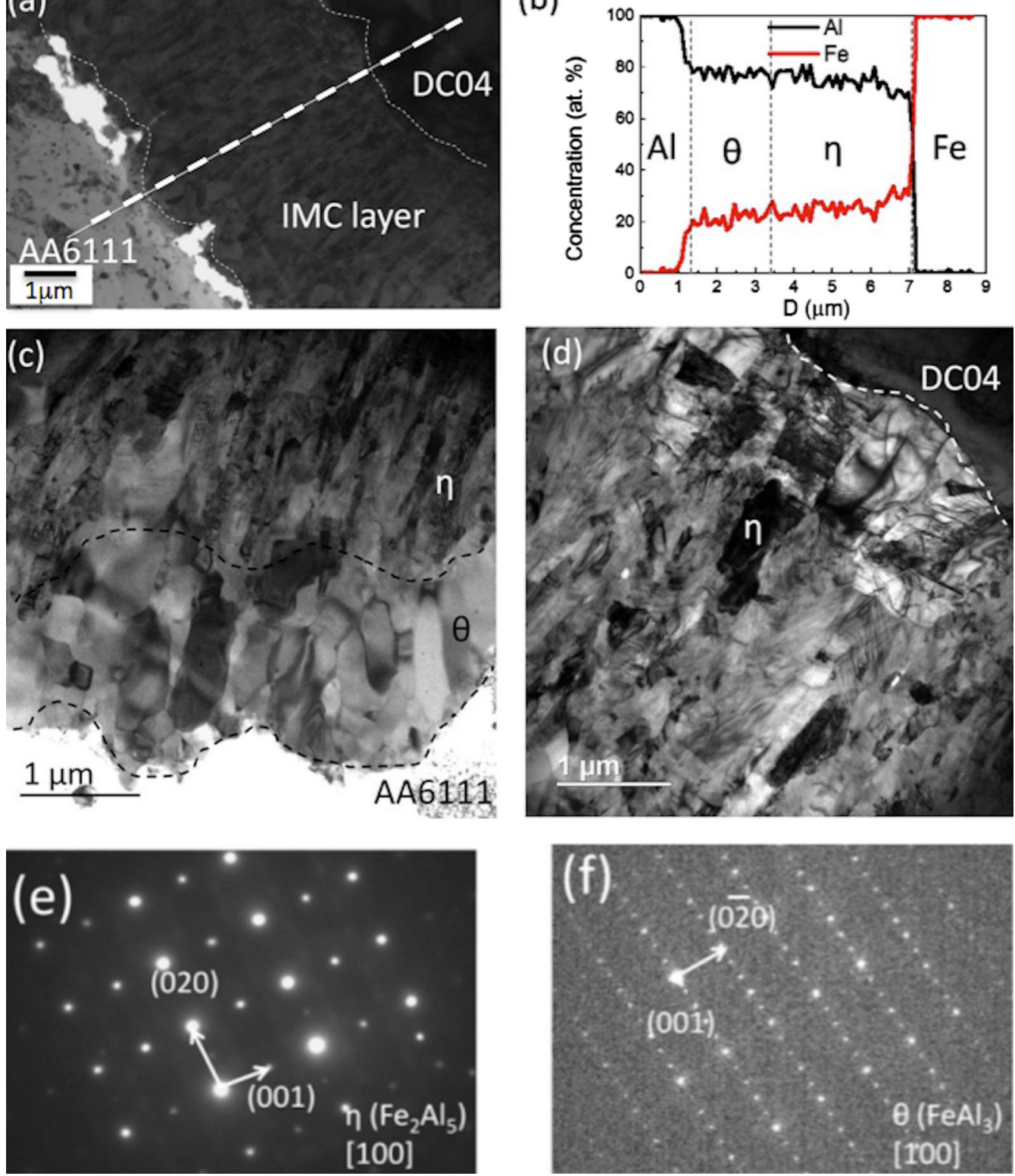

Fig. 3-(a) The IMC layer at the interface of the UMW joint in the as-welded state (1.5 s UMW). (b) Composition profile along line shown in (a) across the IMC layer. $(c)$ and $(d)$ IMC layer after annealing at $773 \mathrm{~K}\left(500^{\circ} \mathrm{C}\right)$ for 10 min (note the different scales), with example diffraction patterns from $(e)$ the $\eta$ and $(f) \theta$ phases obtained from the annealed sample. 
easily in the IMC layer, especially in the $\eta$ phase as it comprised the major part of the layer. It should be noted that the large crack seen in this sample between the $\theta$ phase and aluminum substrate occurred during sample preparation.

The overall average thicknesses of each IMC sublayer measured from SEM images are shown in Figure 5 [for isothermal annealing at $723 \mathrm{~K}$ and $773 \mathrm{~K}\left(450{ }^{\circ} \mathrm{C}\right.$ and $\left.\left.500{ }^{\circ} \mathrm{C}\right)\right]$. The thickness of both phases in the layer at $723 \mathrm{~K}\left(450{ }^{\circ} \mathrm{C}\right)$ can be seen to follow parabolic kinetics, with the data being well fitted by a straight line when plotted against the square root of time. At $773 \mathrm{~K}$ $\left(500{ }^{\circ} \mathrm{C}\right)$, the data for shorter times also closely follow parabolic kinetics. However, the data-point after 2 hours annealing $\left(t^{0.5}=85 \mathrm{~s}^{0.5}\right)$ reveals a large deviation from the trend line at shorter times. At this time, the $\eta$ phase has grown much thicker than expected from parabolic extrapolation, and the $\theta$ phase is thinner. This is indicative of a regime where the $\eta$ phase starts to grow at the expense of the $\theta$ phase as well as continuing to grow into the ferrite (Table II).

From this data and other measurements performed at annealing temperatures in the range $653 \mathrm{~K}$ to $833 \mathrm{~K}$ $\left(380{ }^{\circ} \mathrm{C}\right.$ to $\left.560^{\circ} \mathrm{C}\right)$, a value of the effective activation
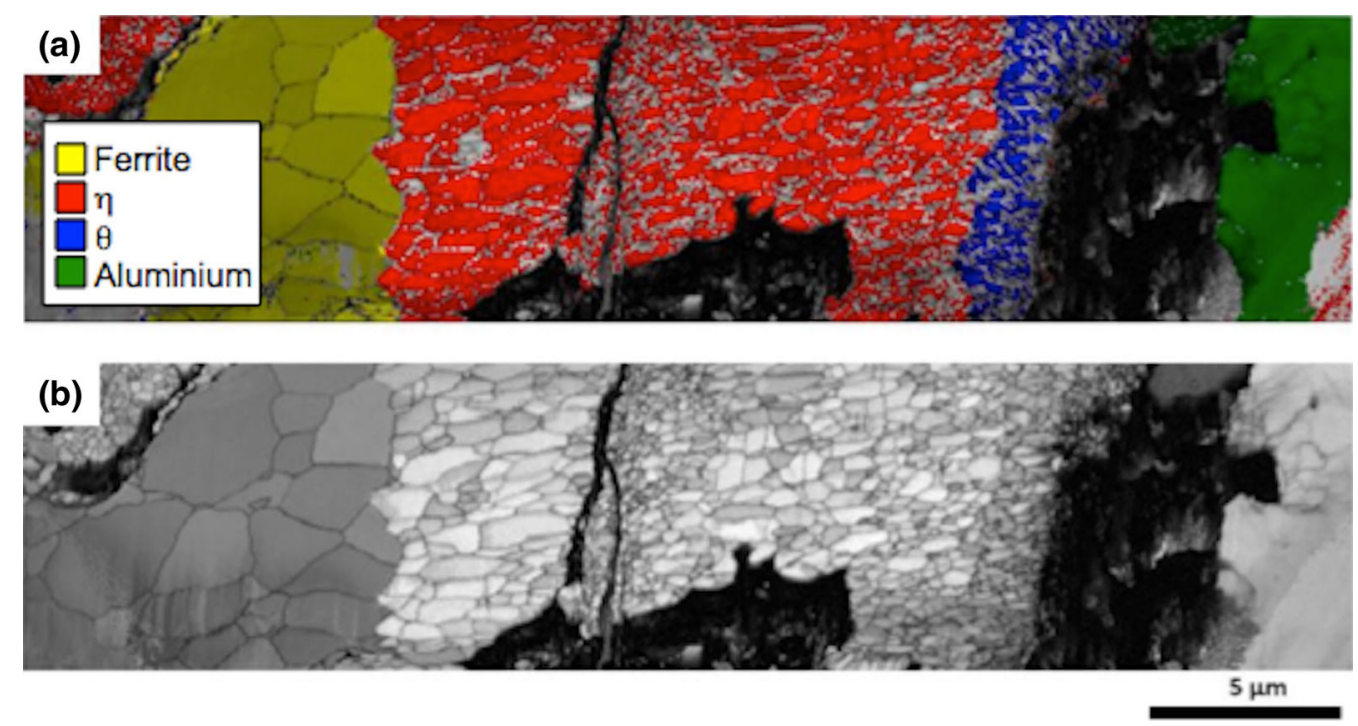

Fig. 4 -EBSD (a) phase and (b) pattern quality maps showing the grain structure in each sublayer, after annealing at $773 \mathrm{~K}\left(500{ }^{\circ} \mathrm{C}\right)$ for $2 \mathrm{~h}$.

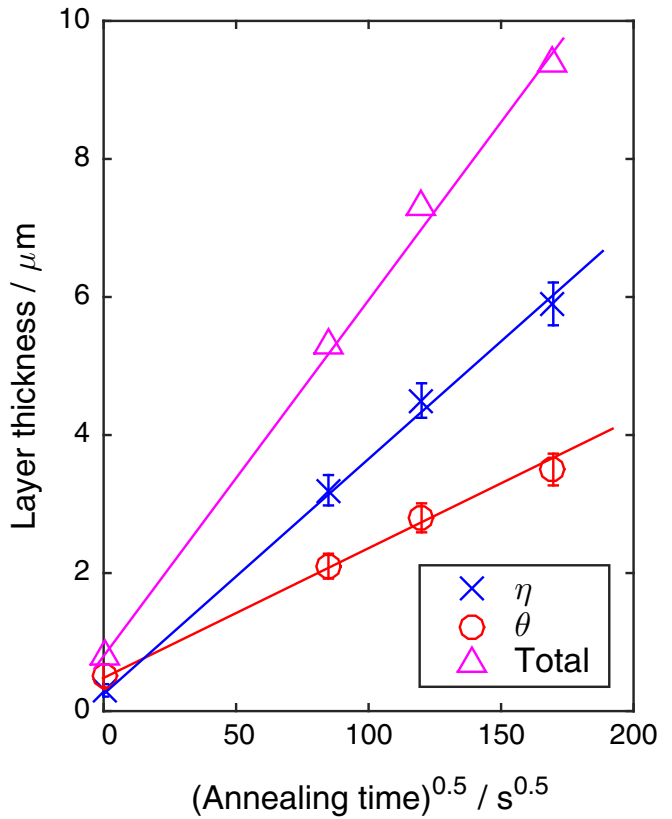

(a)

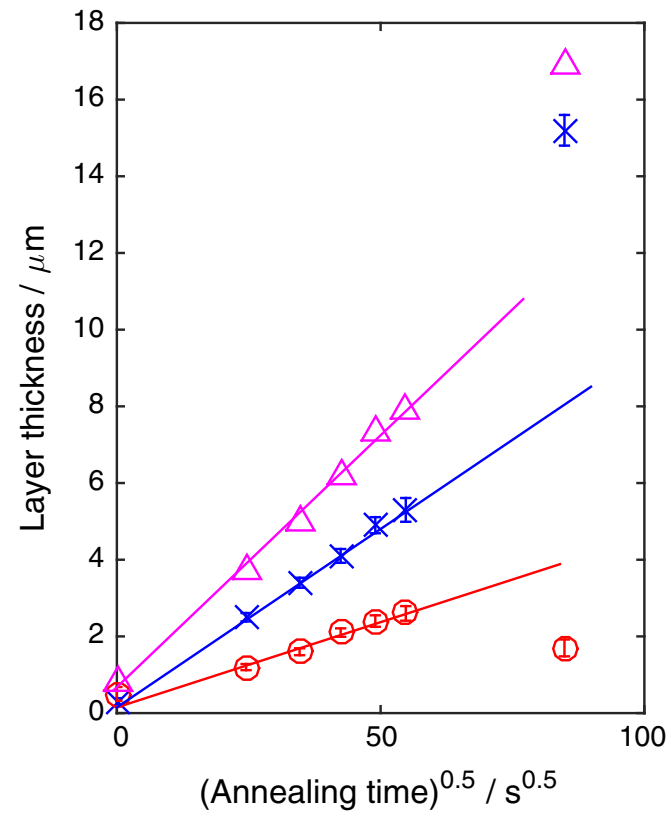

(b)

Fig. 5-Measured thickness of $\eta$ phase and $\theta$ phase at $(a) 723 \mathrm{~K}\left(450{ }^{\circ} \mathrm{C}\right)$ and $(b) 773 \mathrm{~K}\left(500{ }^{\circ} \mathrm{C}\right)$ and total thickness $(\eta+\theta)$. Lines correspond to the best fit to a parabolic relationship. 
Table II. Nominal Chemical Compositions (Weight Percent) of the Materials

\begin{tabular}{lcccccccccc}
\hline & \multicolumn{7}{c}{ Chemical Compositions (Wt Pct) } \\
\cline { 2 - 10 } Material & $\mathrm{Al}$ & $\mathrm{Fe}$ & $\mathrm{Mg}$ & $\mathrm{Mn}$ & $\mathrm{Si}$ & $\mathrm{Cu}$ & $\mathrm{S}$ & $\mathrm{C}$ & $\mathrm{Zn}$ \\
\hline $6111-\mathrm{T} 4$ & bal & 0.26 & 0.58 & 0.20 & 0.82 & 0.59 & - & - \\
DC04 & 0.025 & bal & - & 0.40 & - & - & 0.03 & 0.08 & - \\
\hline
\end{tabular}

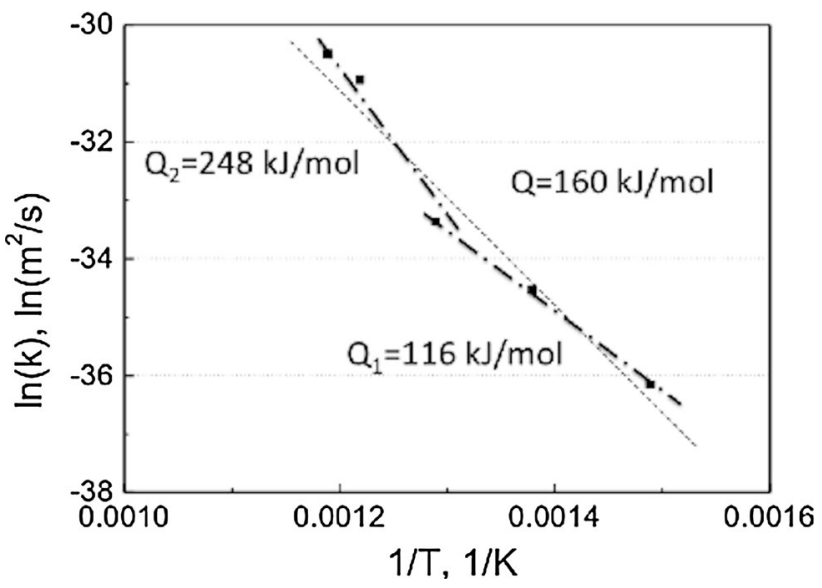

Fig. 6-Arrhenius plot of measured values of the parabolic rate constant derived from experimental thickness measurements. The effective activation energies determined by a best fit across the whole temperature range and by two fits in the high and low temperature range are shown.

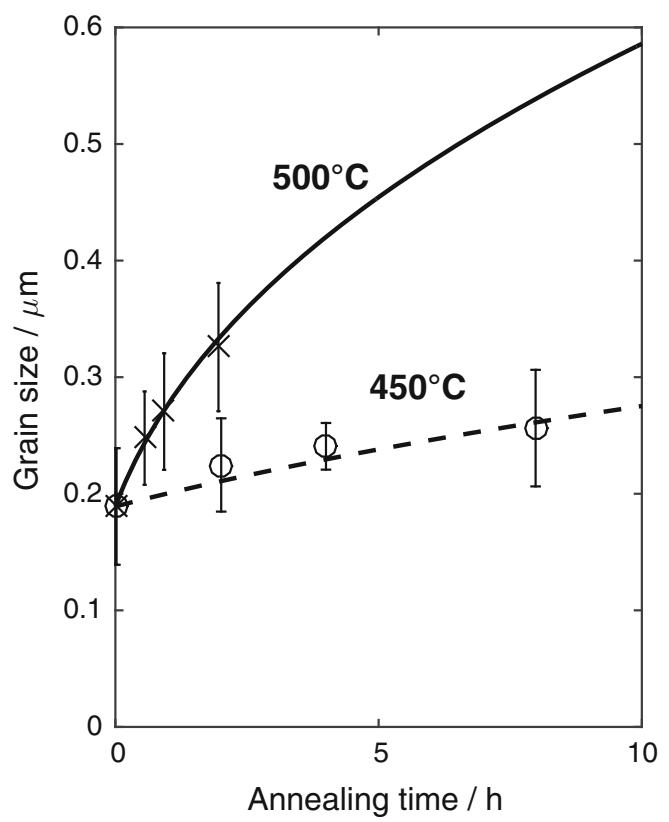

(a) energy for the thickening of the $\eta$ phase (Eq. [2]) can be obtained by linear regression (Figure 6). If a single line is fitted across the whole temperature range, then a value of $Q=160 \mathrm{~kJ} \mathrm{~mol}^{-1}$ is derived, which is in the range of the published values in Table I. However, a better fit can be obtained by considering two temperature regimes, giving effective $Q$ values of 248 and $116 \mathrm{~kJ} \mathrm{~mol}^{-1}$, in the high and low temperature range [above and below $753 \mathrm{~K}$ $\left(480{ }^{\circ} \mathrm{C}\right)$ ], respectively (Figure 6). Although the number of data-points on which this interpretation is based is clearly limited, the transition in the effective $Q$ value is indicative of a change of rate controlling mechanism, an observation which will be explored in detail later.

\section{B. Grain Coarsening}

The change in grain size, seen in each phase in the IMC layer measured by TEM with increasing heat treatment times at $723 \mathrm{~K}$ and $773 \mathrm{~K}\left(450^{\circ} \mathrm{C}\right.$ and $500{ }^{\circ} \mathrm{C}$ ), is shown in Figure 7. For the columnar grains, their average width in the plane of the interface was measured, because this dimension is most relevant to the

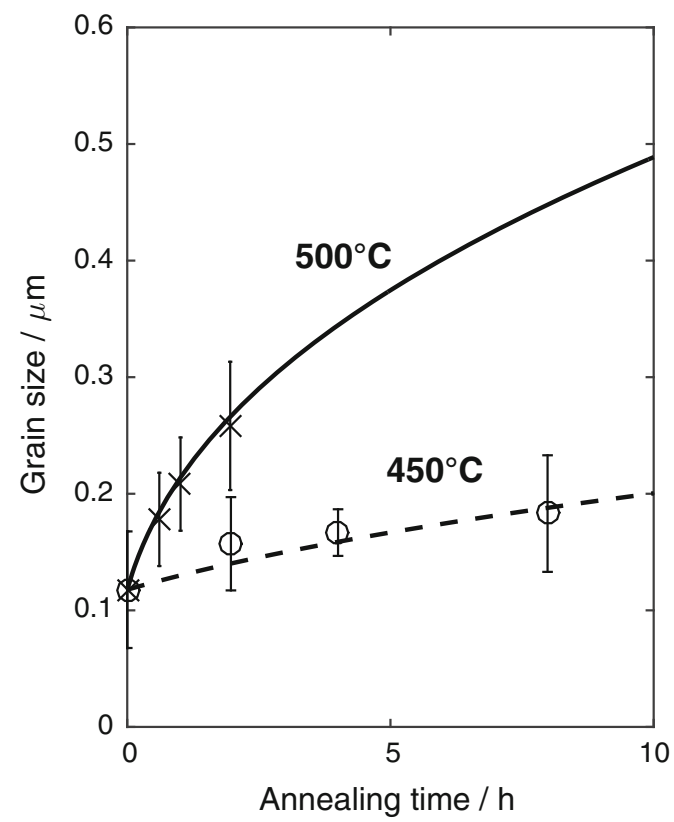

(b)

Fig. 7-Average grain width of the $(a) \eta$ phase and $(b) \theta$ phase as a function of annealing time, fitted using the classical grain growth law in equation. ${ }^{[9]}$ 
effect of grain boundary area on diffusion through the layer. Figure 7 shows the experimental data and the fit to the grain growth law expressed in Reference 5. The best-fit values for the grain growth law (Eq. [5]) are also shown in Table III. Since these parameters are determined by fits to limited experimental data, it is important not to ascribe physical significance to their values. Nevertheless, the similar values for the activation energy suggest that similar physical processes are controlling grain growth in both phases.

It is also noteworthy that in practice the grain size and structure in the IMC phases is highly heterogeneous, as can be seen in the micrographs and EBSD map (Figures 3 and 4). This reflects the history of the layer growth, since the grains in the layer were not all nucleated at the same time. At the reaction front (interface between phases), new IMC grains nucleate and initially a very fine, but equiaxed, structure is obtained. Deeper into the layer, the preferential growth of some grains over others leads to an evolution of a

Table III. Exponent (n), Activation Energy $Q_{g g}$, and Pre-factor $K_{0 g g}$ for the Grain Growth Law for $\eta$ and $\theta$ Phases Derived from Fitting Measurements

\begin{tabular}{lccc}
\hline Phase & $n$ & $Q_{g g}(\mathrm{~kJ})$ & $K_{0 g g}\left(\mathrm{~m}^{\mathrm{n}} \mathrm{s}^{-1}\right)$ \\
\hline$\eta$ & 2.5 & 216 & $2.71 \times 10^{-6}$ \\
$\theta$ & 2.5 & 233 & $2.51 \times 10^{-5}$ \\
\hline
\end{tabular}

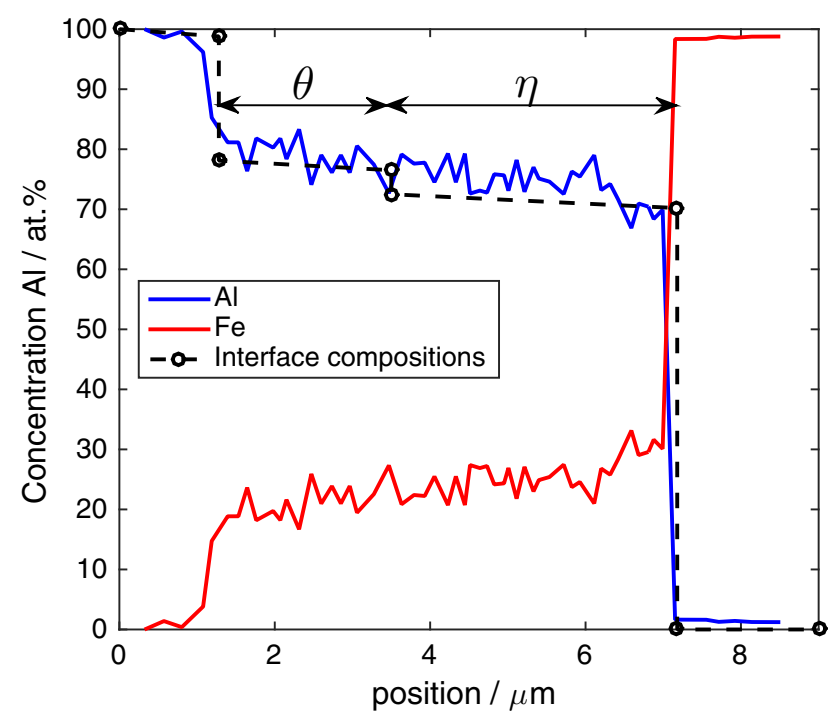

Fig. 8-Measured composition profile across the intermetallic layer after annealing at $773 \mathrm{~K}\left(500{ }^{\circ} \mathrm{C}\right)$ for $1 \mathrm{~h}$ showing the interfacial compositions, used in fitting the model. columnar grain structure. The fine, equiaxed grains are thus those that nucleated last and have had least growth time. However, from the point of controlling growth rate of the layer, it is diffusion through the columnar grain structure that will be rate limiting. This is because this region dominates the thickness of the layer and also provides the fewest fast diffusion pathways (grain boundaries). It is for this reason that the grain size in the columnar zone is used in the model.

\section{Diffusion-Controlled Growth Rates}

The effective interdiffusion coefficients were calculated for each of the experimental measurements shown in Figure 5 following the procedure described in Reference 8. For each point, the layer thickness and measured interfacial compositions allow the instantaneous value of the effective interdiffusion coefficient to be calculated. An example of the interfacial compositions derived from a measured compositions line profile is shown in Figure 8 $\left[773 \mathrm{~K}\left(500{ }^{\circ} \mathrm{C}\right), 1\right.$ hour]. Due to the composition fluctuations in the profile, it was necessary to use microscopy to identify the interface composition, and correlate this with the position along the composition line profile. Note that, the compositions of the $\eta$ and $\theta$ phases were consistently found to vary somewhat from their ideal stoichiometry $\left(\mathrm{Fe}_{2} \mathrm{Al}_{5}\right.$ and $\mathrm{FeAl}_{3}$, respectively) and the composition transition at the interface between the two phases is also less than expected from stoichiometry.

The effective diffusivities extracted from this analysis are shown in Figure 9, where it can be noted that the effective diffusion rate decreases with increasing heat treatment time, particularly at the higher temperature where more rapid grain growth occurs. Using the fitted grain size data, the estimated relative proportion of grain boundary area for diffusion was calculated using Eq. [4] at each temperature for each annealing time. The interdiffusion coefficients for lattice and grain boundary diffusion of each phase were then determined from the effective interdiffusion coefficient (using Eq. [3]) and the grain size data in Figure 7.

By performing this analysis for all the temperatures at which measurements were made, the pre-exponential factor and activation energy can be fitted to provide the best prediction of the lattice and grain boundary interdiffusion coefficients at both temperatures. The results of this analysis are shown in Table IV. It can be seen that the activation energies for lattice and grain boundary interdiffusion are consistently slightly larger for the $\eta$ than $\theta$ phase. In addition, the activation energy for grain boundary interdiffusion is determined to be approximately half that for lattice diffusion, which is consistent with expectations. ${ }^{[10]}$ The temperature independent prefactor for the $\eta$ phase derived from this

Table IV. Calculated Pre-factor and Activation Energy for Lattice $(l)$ and Grain Boundary ( $g b$ ) Diffusion Coefficient in the Two IMC Phases

\begin{tabular}{lcccc}
\hline Phase & $D_{l 0}\left(\mathrm{~m}^{2} \mathrm{~s}^{-1}\right)$ & $D_{g b 0}\left(\mathrm{~m}^{2} \mathrm{~s}^{-1}\right)$ & $Q_{l}\left(\mathrm{~kJ} \mathrm{~mol}^{-1}\right)$ & $Q_{g b}\left(\mathrm{~kJ} \mathrm{~mol}^{-1}\right)$ \\
\hline$\eta\left(\mathrm{Fe}_{2} \mathrm{Al}_{5}\right)$ & 500 & $5 \times 10^{-4}$ & 240 & 120 \\
$\theta\left(\mathrm{FeAl}_{3}\right)$ & 3 & $3 \times 10^{-5}$ & 220 & 110 \\
\hline
\end{tabular}




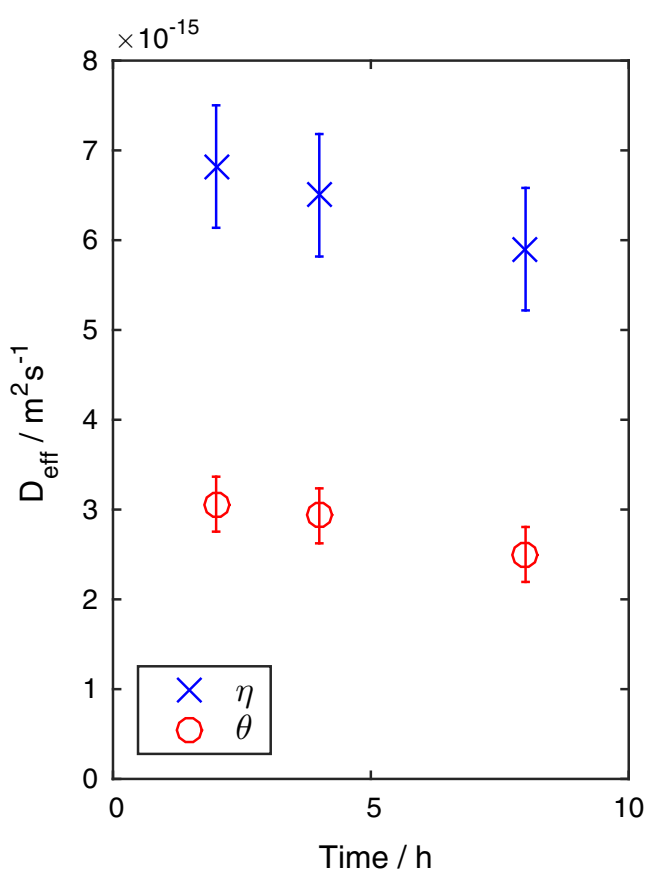

(a)

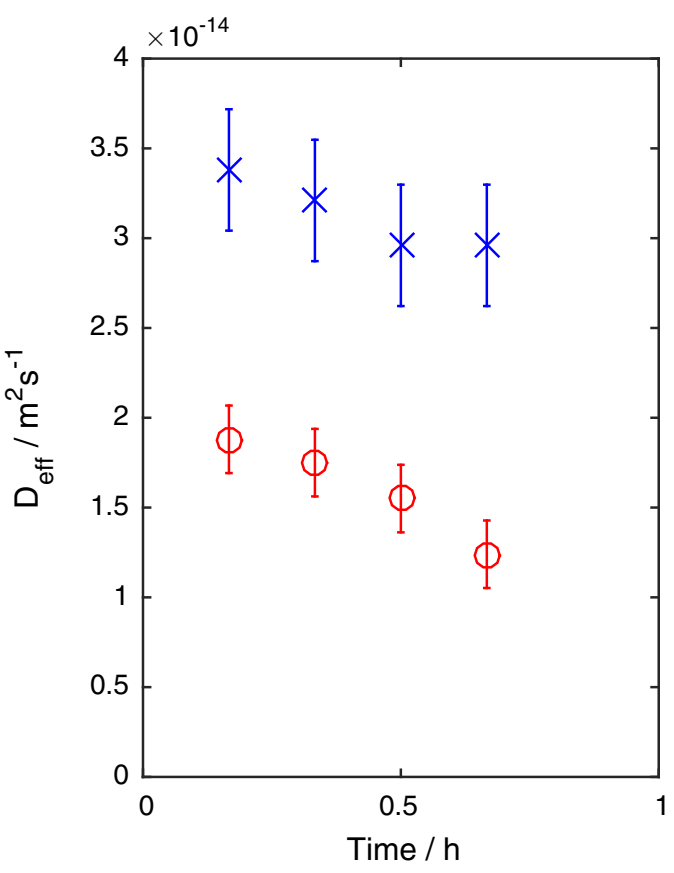

(b)

Fig. 9-Effective interdiffusion coefficient for $\eta$ and $\theta$ phases as a function of annealing time at $(a) 723 \mathrm{~K}\left(450{ }^{\circ} \mathrm{C}\right)$ and $(b) 773 \mathrm{~K}\left(500{ }^{\circ} \mathrm{C}\right)$ derived from thickness and interfacial composition measurements.

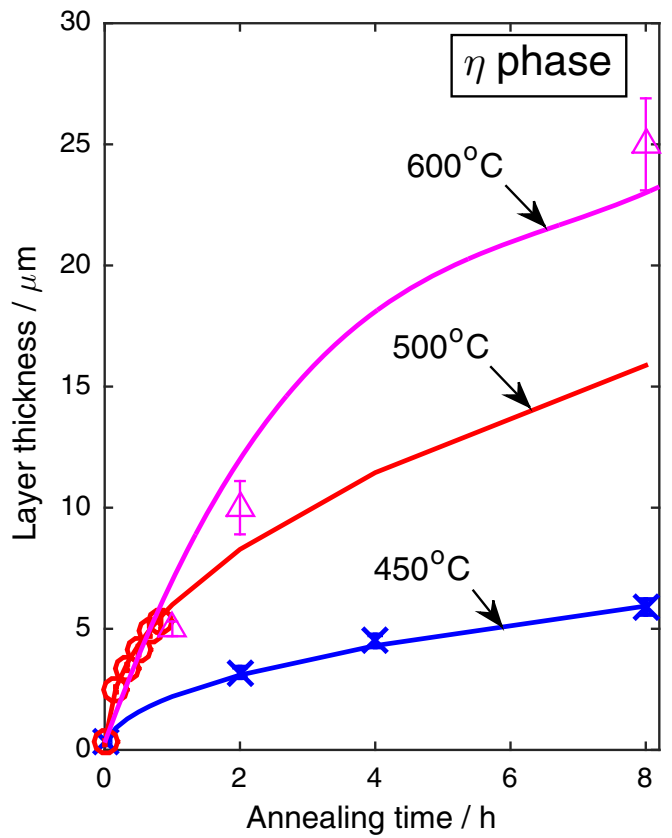

(a)

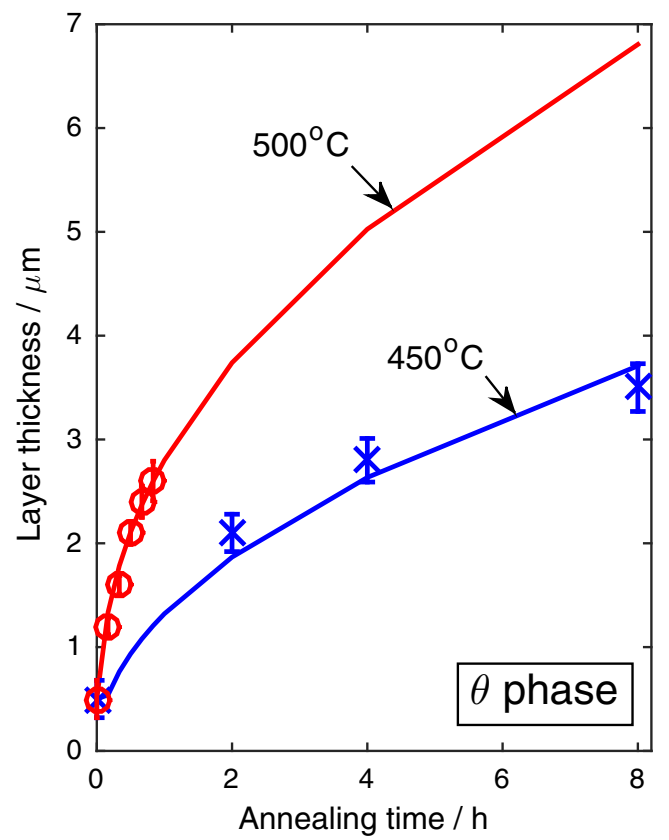

(b)

Fig. 10-Prediction and experimental results of the thickness of $(a) \eta$ phase and $(b) \theta$ phase IMC layers as a function of annealing time. The experimental data at $873 \mathrm{~K}\left(600^{\circ} \mathrm{C}\right)$ were obtained from the results of Springer. ${ }^{[3]}$

analysis is also over an order of magnitude greater than that for the $\theta$ phase when considering both lattice and grain boundary diffusion, and this leads to the faster growth of the $\eta$ phase despite the slightly greater activation energy for interdiffusion in this case.

\section{Validation of the Model}

In order to validate the model, once the interdiffusion coefficients were determined, the thickness of each phase was predicted using the dual phase diffusion model, including the fitted grain growth model, as a function of 
annealing time during static heat treatment under isothermal conditions. Predictions at $723 \mathrm{~K}$ and $773 \mathrm{~K}$ $\left(450{ }^{\circ} \mathrm{C}\right.$ and $500{ }^{\circ} \mathrm{C}$ ) are compared to the experimental results in Figure 10, where it can be seen that the model is able to give a good fit to the increase in thickness for both phases.

The data-point for the longest annealing time at 773 $\mathrm{K}\left(500{ }^{\circ} \mathrm{C}\right)$ is omitted in this comparison because, as discussed previously, at this time the $\eta$ phase grows by consuming the $\theta$ phase, and the assumption that growth is controlled by diffusion through the layer on which the model is based is no longer valid. Encouragingly, It can also be seen that the model was also able to give a good prediction for "unseen data," that being the thickness of the $\eta$ phase at $873 \mathrm{~K}\left(600{ }^{\circ} \mathrm{C}\right)$ determined by Springer et al., ${ }^{[3]}$ a temperature that is $100 \mathrm{~K}\left(-173{ }^{\circ} \mathrm{C}\right)$ above the range used for model calibration.

\section{E. Importance of Grain Boundary Diffusion to the IMC Growth Rate}

The model allows the contribution of grain boundary and lattice diffusion to be separated for each phase, providing an important insight into the dominant

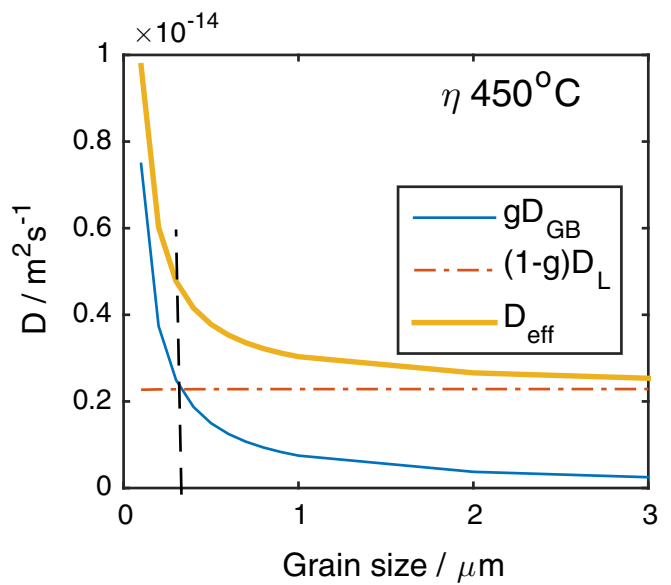

(a)

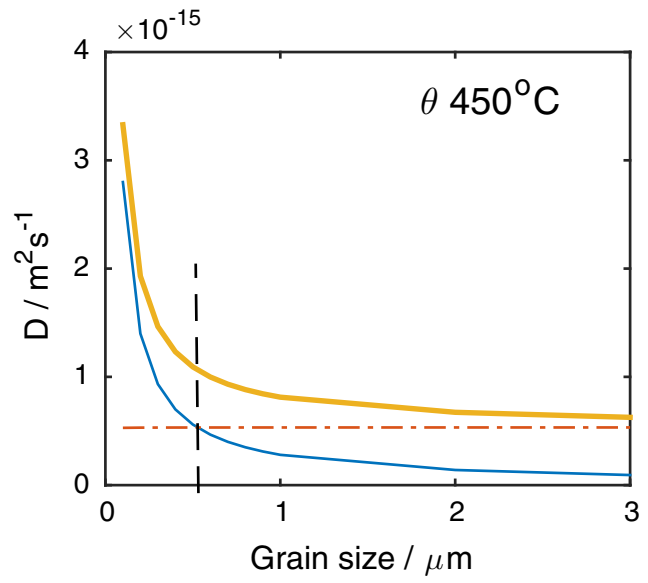

(c) mechanism under a given set of growth conditions. Figure 11 shows a plot of the grain boundary and lattice components to the overall effective diffusion coefficient for $\eta$ and $\theta$ phases at $723 \mathrm{~K}$ and $773 \mathrm{~K}\left(450{ }^{\circ} \mathrm{C}\right.$ and $500{ }^{\circ} \mathrm{C}$ ) as a function of grain size in the IMC layer. At a given temperature, the contribution from lattice diffusion is approximately constant for each phase. Clearly, the contribution from grain boundary diffusion decreases strongly as the grain size increases. This means there is a critical grain size at which there is a transition from lattice to grain boundary domination of diffusion (a vertical dashed line on the plots indicates this transition). As temperature increases [e.g., going from $723 \mathrm{~K}$ to $773 \mathrm{~K}\left(450{ }^{\circ} \mathrm{C}\right.$ to $\left.500{ }^{\circ} \mathrm{C}\right)$ ] the critical grain size below which grain boundary diffusion becomes dominant is reduced, as expected. This is because the diffusion rate increases as temperature increases.

For all phases, and at both temperatures, it can be seen that grain boundary diffusion only becomes dominant in the sub-micron range (grain sizes $<0.5 \mu \mathrm{m}$ ). However, as demonstrated, the IMC grain sizes that are obtained in practice are in this range, so that the dominant mechanism would be expected to transition

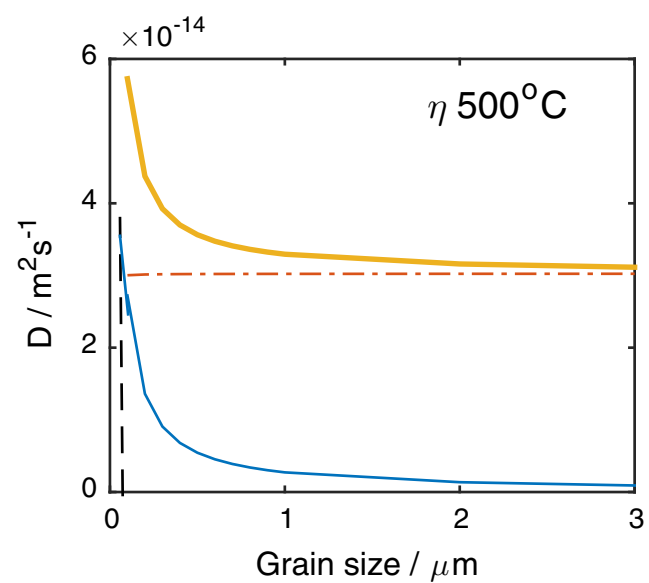

(b)

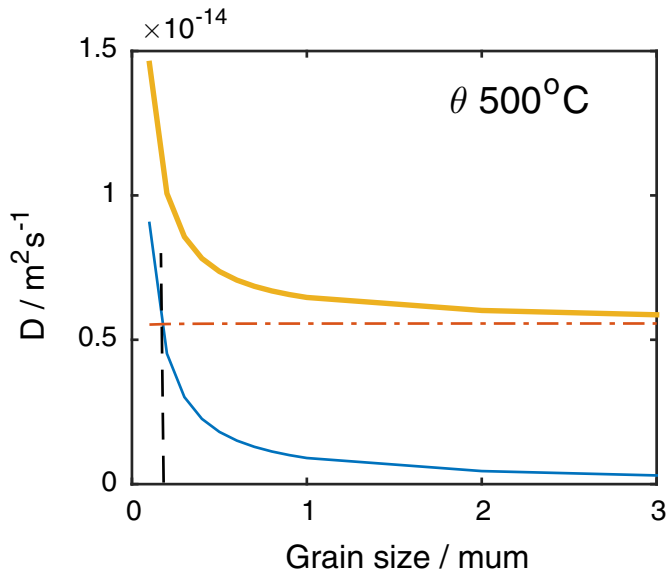

(d)

Fig. 11- The contributions of grain boundary diffusion coefficient $\left(\mathrm{g} D_{\mathrm{gb}}\right)$ and lattice diffusion coefficient $\left((1-\mathrm{g}) D_{1}\right)$ to the effective diffusion coefficient $\left(D_{\text {eff }}\right)$, as a function of grain size for $(a)$ the $\eta$ phase at $723 \mathrm{~K}\left(450{ }^{\circ} \mathrm{C}\right),(b)$ the $\eta$ phase at $773 \mathrm{~K}\left(500{ }^{\circ} \mathrm{C}\right),(c)$ the $\theta$ phase at $723 \mathrm{~K}$ $\left(450{ }^{\circ} \mathrm{C}\right),(d)$ the $\theta$ phase at $773 \mathrm{~K}\left(500{ }^{\circ} \mathrm{C}\right)$. 


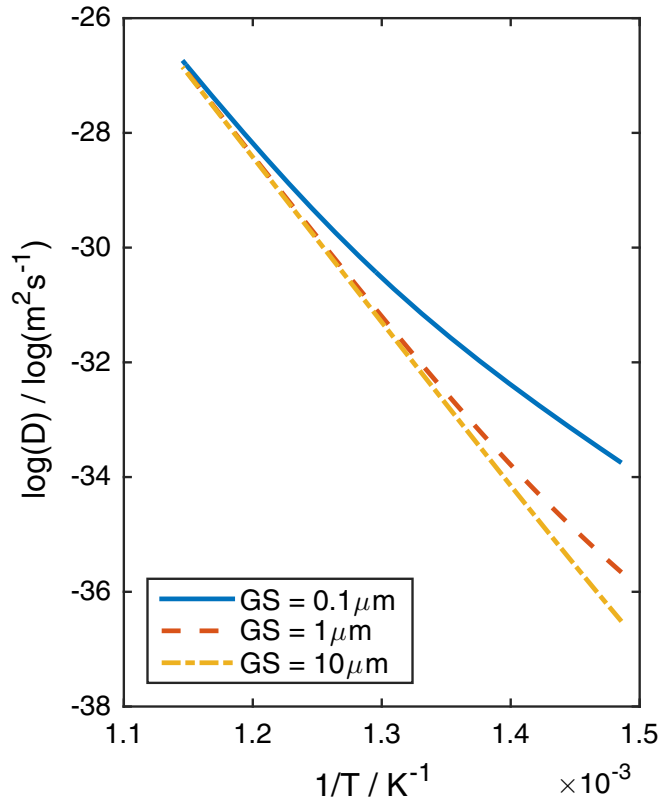

(a)

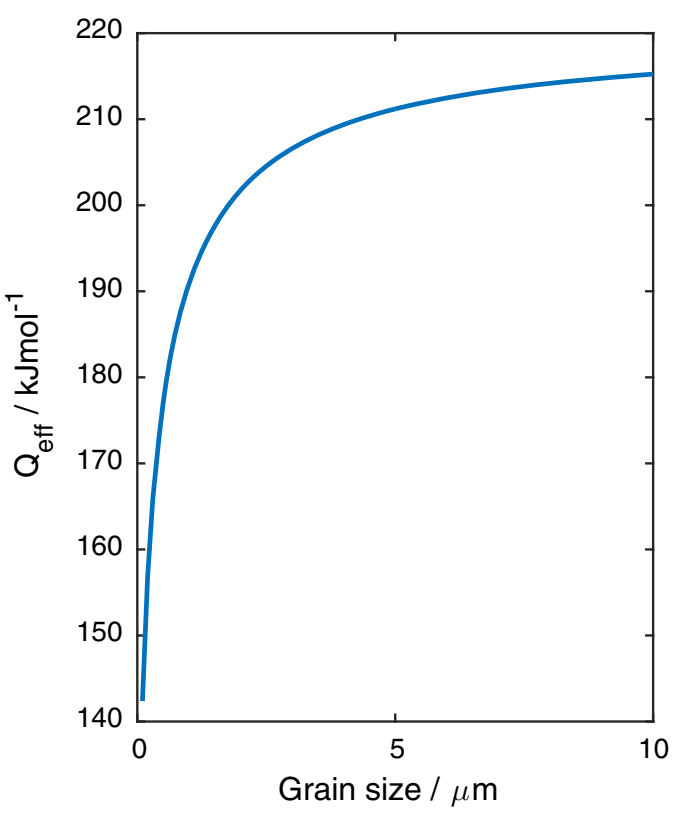

(b)

Fig. 12-(a) Arrhenius plot showing effective diffusion coefficient as a function of $1 / T$ accounting for both lattice and grain boundary diffusion for three grain sizes $(0.1,1,10 \mu \mathrm{m})$. (b) Effective activation energy derived from Arrhenius plots of effective diffusion coefficient as a function of grain size.

from grain boundary diffusion to lattice diffusion as temperature increases. This is consistent with the change in slope in the activation energy curve previously noted in Figure 6.

To understand the role of grain boundary diffusion in explaining the wide range of activation energies reported in the literature, the procedure used experimentally to determine activation energy can be repeated, but using model predictions with known grain size rather than experimental data. Figure 12(a) shows a plot of $\log (D)$ (the effective diffusion coefficient) against $(1 / T)$, calculated for different grain sizes using the model. If a single diffusion pathway dominates, such a plot is expected to be a straight line, the gradient of which is used to determine the effective activation energy. It can be seen that as the grain size reduces into the range measured experimentally $(<1 \mu \mathrm{m})$ the increased contribution from grain boundary diffusion leads to a curvature in the line due to the mix of diffusion pathways. Data from experiments performed under such conditions are not therefore expected to fit a straight line,${ }^{[12]}$ but typical practice in the literature is to neglect this effect and attempt a single linear fit. This is done because the error bars on the data are usually large, and the curvature of the line is often hidden within the range of the error. However, as demonstrated in Figure 6, careful inspection of the experimental data reveals that multiple straight lines, which better fit the theoretical curve, better approximate the trend.

If a single line fit is used, a range of effective activation energies will be derived depending on grain size in the layer. Figure 12(b) shows the effective activation energies that would be deduced by fitting a single straight line across a grain size range from 0.1 to $10 \mu \mathrm{m}$. It can be seen that across this range, the effective activation energy varies by a factor of about 1.5 . A variation of this magnitude can explain most of the variation in effective activation energies reported in the literature.

This means that whilst alloy composition undoubtedly has some effect in changing the activation energy, it is likely that the most important and generally neglected effect is the contribution of grain boundary diffusion. Note that, this is a particular issue in $\mathrm{Fe}-\mathrm{Al}$ couples because the combination of the IMC grain size and the activation energies for diffusion along grain boundaries and in the lattice mean that at typical annealing temperatures $673 \mathrm{~K}$ to $873 \mathrm{~K}\left(400{ }^{\circ} \mathrm{C}\right.$ to $\left.600{ }^{\circ} \mathrm{C}\right)$, the system is in the range where there is a transition from grain boundary to lattice dominated diffusion. This in turn is due to the low homologous temperature in the iron-aluminide phases, which is limited by the relatively low melting point of aluminum.

\section{CONCLUSIONS}

The formation and growth of the intermetallic compound (IMC) layer formed when an aluminum alloy (6111-T4) is joined to an automotive steel (DC04) has been studied in detail and predicted, using a novel model that captures all of the key physical mechanisms, including grain boundary diffusion and the effect of grain coarsening in the IMC layer.

1. The IMC layer consists of two intermetallic phases, $\eta\left(\mathrm{Fe}_{2} \mathrm{Al}_{5}\right)$ on the steel side and $\theta\left(\mathrm{FeAl}_{3}\right)$ on the aluminum side. The $\eta$ phase is the fastest growing, 
and makes the dominant contribution to the overall layer thickness.

2. Both IMC phases are characterized by an ultrafine grain structure, with grain sizes in the range 0.1-0.2 $\mu \mathrm{m}$ before heat treatment. As the layer thickens, the grains grow, but remain less than $1 \mu \mathrm{m}$ in size, even after 10 hours annealing at $773 \mathrm{~K}\left(500{ }^{\circ} \mathrm{C}\right)$.

3. A model developed previously for $\mathrm{Mg}-\mathrm{Al}$ couples was applied to the present case. Using the model, the activation energies for the grain boundary and lattice diffusion were calculated to be 240 and 120 $\mathrm{kJ} \mathrm{mol}^{-1}$ in the $\eta$ phase, and 220 and $110 \mathrm{~kJ} \mathrm{~mol}^{-1}$ in the $\theta$ phase, respectively.

4. The model shows that both lattice and grain boundary diffusion make a significant contribution to the overall solute flux, with a transition from grain boundary to lattice dominated diffusion on increasing temperature. Attempting to fit thickening data to a single activation energy is therefore not physically valid.

\section{ACKNOWLEDGMENTS}

The authors would like to thank the Engineering and Physical Sciences Research Council (EPSRC) for funding this work through the LATEST2 program (EP/H020047/1). The data used in this paper may be obtained by contacting the corresponding author.

\section{OPEN ACCESS}

This article is distributed under the terms of the Creative Commons Attribution 4.0 International
License (http://creativecommons.org/licenses/by/4.0/), which permits use, duplication, adaptation, distribution and reproduction in any medium or format, as long as you give appropriate credit to the original author(s) and the source, provide a link to the Creative Commons license and indicate if changes were made.

\section{REFERENCES}

1. L. Xu, L. Wang, Y.-C. Chen, J.D. Robson, and P.B. Prangnell: Metall. and Mater. Trans. A, 2016, vol. 47A, pp. 334-46.

2. A. Panteli, J.D. Robson, I. Brough, and P.B. Prangnell: Mater. Sci. Eng. A, 2012, vol. 556A, pp. 31-42.

3. H. Springer, A. Kostka, J.F. Dos Santos, and D. Raabe: Mater. Sci. Eng. A, 2011, vol. 528A, pp. 4630-42.

4. H. Springer, A. Kostka, E.J. Payton, D. Raabe, A. Kaysser-Pyzalla, and G. Eggeler: Acta Mater., 2011, vol. 59, pp. 1586-1600.

5. T. Tanaka, T. Morishige, and T. Hirata: Scr. Mater., 2009, vol. 61, pp. $756-59$.

6. D. Naoi and M. Kajihara: Mater. Sci. Eng. A, 2007, vol. 459, pp. 375-82.

7. M. Kajihara: Acta Mater., 2004, vol. 52, pp. 1193-200.

8. L. Wang, Y. Wang, P. Prangnell, and J. Robson: Metall. Mater. Trans. A, 2015, vol. 46A, pp. 4106-14.

9. M. Kajihara: Mater. Sci. Eng. A, 2005, vol. 403, pp. 234-40.

10. H. Mehrer: Diffusion in solids: Fundamentals, methods, materials, diffusion-controlled process, Springer, Berlin, 2007, pp. 161-77.

11. H.V. Atkinson: Acta Metall., 1988, vol. 36, pp. 469-91.

12. A.S. Nowick and G.J. Dienes: Phys. Status Solidi (B), 1967, vol. 24 , pp. $461-7$.

13. A. Bouayad, C. Gerometta, A. Belkebir, and A. Ambari: Mater. Sci. Eng. A, 2003, vol. 363, pp. 53-61.

14. S.G. Denner and R.D. Jones: Metals Technol., 1977, vol. 3, pp. $167-73$.

15. G. Eggeler, W. Auer, and H. Kaesche: J. Mater. Sci., 1986, vol. 21, pp. $3348-50$.

16. N. Tang, Y.P. Li, S. Kurosu, Y. Koizumi, H. Matsumoto, and A. Chiba: Corros. Sci., 2012, vol. 60, pp. 32-7. 